\title{
Note d'intention pour Plaidoirie pour vendre le Congo
}

\section{Sinzo Aanza}

\section{OpenEdition}

\section{Journals}

Édition électronique

URL : https://journals.openedition.org/coma/6212

DOI : $10.4000 /$ coma. 6212

ISSN : 2275-1742

\section{Éditeur}

Institut des textes \& manuscrits modernes (ITEM)

\section{Référence électronique}

Sinzo Aanza, « Note d'intention pour Plaidoirie pour vendre le Congo », Continents manuscrits [En ligne], 15 | 2020, mis en ligne le 15 octobre 2020, consulté le 13 janvier 2023. URL : http:// journals.openedition.org/coma/6212 ; DOI : https://doi.org/10.4000/coma.6212

Ce document a été généré automatiquement le 13 janvier 2023.

\section{(c) (i) (3)}

Creative Commons - Attribution - Pas d'Utilisation Commerciale - Pas de Modification 4.0 International - CC BY-NC-ND 4.0

https://creativecommons.org/licenses/by-nc-nd/4.0/ 


\title{
Note d'intention pour Plaidoirie pour vendre le Congo
}

\author{
Sinzo Aanza
}

\section{NOTE DE L'ÉDITEUR}

Plaidoirie pour vendre le Congo (2020) a été mis en scène en septembre-octobre 2020 dans le cadre de la $11^{\mathrm{e}}$ édition des Récréâtrales à Ouagadougou par Aristide Tarnagda (Burkina Faso, compagnie théâtrale Acclamations), que Sinzo Aanza avait rencontré dans le cadre des «Praticables » à Bamako, pour la mise en scène du texte Le Jour du massacre (2017, compagnie Osase, metteur en scène : Philip Boulay ; production : Tarmac des Auteurs et festival « Ça se passe à Kin »). La première en Europe de Plaidoirie pour vendre le Congo a lieu en novembre 2020 avec deux représentations au Théâtre Jean Vilar de Vitry-sur-Seine. 


\section{Sinzo AANZA}

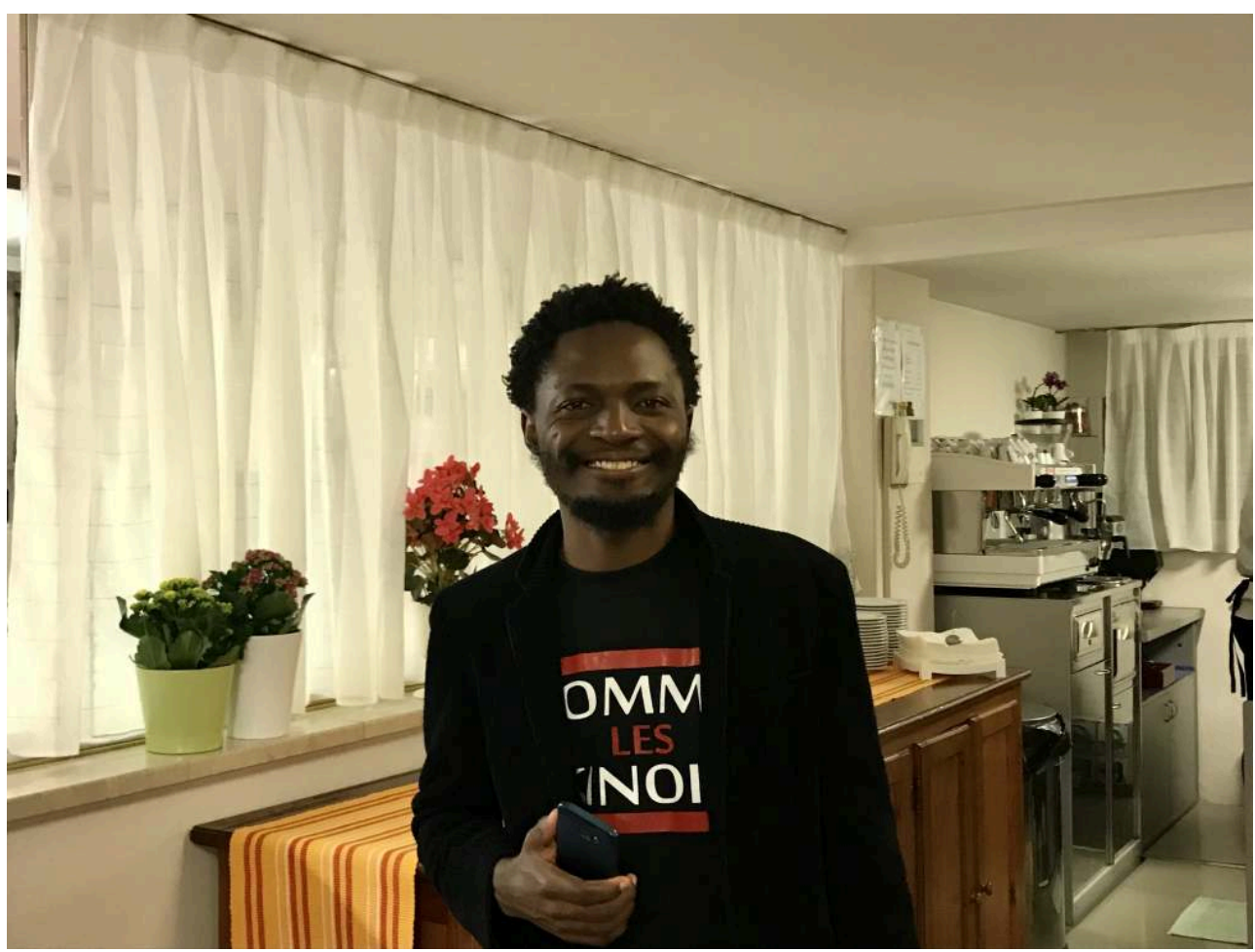

1 La vente du Congo vient du souvenir de la saleté de la mort, ou de l'idée que je me suis fait de la saleté de la mort jusqu'au jour où, après avoir vu, dans les conflictualités installées dans mon Kivu natal par les besoins impérieux de l'économie globalisée, uniquement des cadavres confondus à la poussière ou vautrés dans de l'herbe ou composant avec l'éparpillement d'objets quelconques, je voyais enfin un mort propre, entier, digne dans sa mort. C'était un vieux prêtre plein de mérite qui s'appelait Mabondo avec lequel, la veille, on avait passé l'après-midi à cueillir les goyaves de notre jardin. C'était, aussi loin que remontaient mes souvenirs, la première personne qui me semblait digne dans sa mort ou qui semblait en fait simplement continuer à être un homme dans la mort. Même lorsque je coordonnais, en tant que doyen des petits séminaristes, l'habillage d'apparat de sa dépouille pour la liturgie de veillée, en aucun moment cela ne me sembla être la mort-même, étant habitué à des morts sales et à celles qui n'étaient que de lointaines nouvelles.

2 Ma conscience de la mort me vint elle-même après plusieurs morts sales, celle surtout de Hutus qui tapissaient de leurs corps enroulés dans des nattes les rues de mon quartier à Goma après y avoir été rattrapés, à travers la dysenterie, par la mort que beaucoup d'entre eux avaient participé à donner durant le génocide rwandais, après avoir joué comme beaucoup d'enfants de Goma à la marelle avec ces cadavres abandonnés là comme des déchets circonstanciels, ce fut la mort sale de Nawej, qui partageait mon pupitre en classe de deuxième primaire, avant ce jour où elle fut écrasée par un véhicule sur le lieu que nous traversions tous pour accéder à l'école. Elle, je n'ai jamais vu son corps, au moment où ma classe avait été conviée à lui dire au revoir, j'avais détourné le regard, à cause des petits bouts d'elles qui étaient restés sur l'asphalte et que tout le monde indexait ce matin-là pour dire qu'elle n'avait aucune chance de survivre à ça. 
Durant un colloque à Rutgers University, près de New York, il me fut demandé ce que je voulais voir dans la ville. Le Whitney Museum venait d'ouvrir et les Highlines présentaient une superbe exposition au parcours des flâneurs. Me revenait avec une insistance inconfortable l'image de la saleté envahissante, suffocante, souveraine de tous ces morts qui ont jalonné ma vie et dont certains avaient même été retenus dans le quartier de mon enfance à Goma, ne pouvant être conduits aux cimetières sous les obus et tout le tintamarre affolant des crépitements, si bien qu'ils continuaient à faire partie de la vie du quartier car les petites croix sur leurs tombes étaient des mains qui disaient bonjour et faisaient de petits signes de complicité avec nous ou d'avertissement, je n'avais qu'une obsession : la bourse de New York ! Je ne voulais aller que là, tout le reste pouvait attendre. Je voulais savoir si ce lieu avait la forme d'un mausolée par exemple ou du plus grand mémorial pour la mort sale, me disant qu'il fallait quand même qu'à un moment donné cette mort sale soit nettoyée, même pour l'illusion ou, pour parler spirituellement, pour le symbole. Mais je suis parti de New York avec une déception également souveraine et suffocante : la bourse n'était pas un lieu assez solennel à mon goût et, au contraire, son voisinage en faisait un trou, un asile de fous plus qu'un mausolée. Pas un lieu de mémoire mais un lieu de mortification pour l'esprit, d'oppression extrême pour le corps et de mort pour les sentiments les plus nobles. Je suis parti de là avec la détermination de trouver une autre voie pour nettoyer la mort et c'était, en complicité avec la bourse, d'avoir en mains l'argent qui finit habituellement dans les trous spéculatifs du monde entier, trous aussi vastes et infinis que la vanité de tous ceux qui ont fait le choix de gagner et de retenir les illusions en triant, sans s'arrêter sur le moindre doute, parmi les vivants, les morts et les choses, il fallait vendre le Congo pour, ne serait-ce qu'au seul moment de la prise de cette grave décision, être dans la pleine possession de soi et du territoire, de son histoire, de ses conflits, ses contradictions, ses espoirs, ses vents, ses souffles, en possession de ce que cela veut dire que d'être un homme ou une femme par-delà ce territoire particulier et réaliser pleinement son humanité, quand bien même il faudrait pour cela acheter le monde entier, le monde actuel, passé, à venir, le monde possible, le monde hypothéqué, le monde hypothétique, le monde nécessaire, le monde indispensable, le monde réconcilié, le monde absolu... avec l'argent du Congo, acheter la vie et l'affirmer définitivement, opiniâtrement, en usant de tout ce qui participe à sa négation, à son étouffement, à son gaspillage...

INDEX

Mots-clés : théâtre, littérature congolaise, note d'intention 


\section{AUTEUR}

\section{SINZO AANZA}

Sinzo AANZA est né en 1990 à Goma (RDC), il vit et travaille à Kinshasa. Écrivain dont la pratique se tourne peu à peu vers le champ de l'art contemporain, il s'inspire, autant pour ses œuvres visuelles que littéraires, de l'exploitation des ressources naturelles, de la représentation des identités nationales, de l'image du Congo depuis l'époque coloniale (notamment dans son « Projet d'attentat contre l'image ? ", acte III, 2017, et dans la série « Épreuve d'Allégorie », 2017). En 2015 il a publié le roman Généalogie d'une banalité (Vents d'ailleurs), en 2018 la pièce théâtrale Que ta volonté soit Kin (Éditions Nzoi). 